\title{
MicroRNA-376a inhibits cell proliferation and invasion in osteosarcoma via directly targeting SATB1
}

\author{
GUANGHONG ZHOU ${ }^{1}$, HAO JIANG ${ }^{1}$ and LIPING MA ${ }^{2}$ \\ Departments of ${ }^{1}$ Surgery and ${ }^{2}$ Nursing, China-Japan Union Hospital of Jilin University, Changchun, Jilin 130033, P.R. China
}

Received February 18, 2018; Accepted July 6, 2018

DOI: $10.3892 / \mathrm{mmr} .2018 .9344$

\begin{abstract}
Aberrantly expressed microRNAs (miRs) are implicated in the regulation of osteosarcoma (OS) onset and development. Therefore, key miRs in OS must be identified to develop promising and effective therapeutic targets for patients with OS. In the present study, reverse transcription-quantitative polymerase chain reaction analysis revealed that miR-376a-3p expression was downregulated in OS tissues and cell lines. Additionally, decreased miR-376a expression was associated with tumor size and lymph node infiltration. Restoration of miR-376a expression reduced cell proliferation and invasion of OS. Furthermore, special AT-rich sequence-binding protein 1 (SATB1) was identified as a direct target gene of miR-376a in OS cells. Furthermore, SATB1 was overexpressed in OS tissues and SATB1 overexpression was inversely correlated with the expression level of miR-376a. In addition, ectopic SATB1 expression counteracted the inhibitory effects of miR-376a overexpression on the proliferation and invasion of OS cells. All these results identified that reduced miR-376a expression may be implicated in the mechanism underlying OS progression, suggesting that the miR-376a/SATB1 axis may be a promising novel target for potential therapeutic methods for the effective treatment of patients with OS.
\end{abstract}

\section{Introduction}

Osteosarcoma (OS) is a common primary malignant tumor of the bone and primarily occurs in adolescents and young adults (1). It accounts for $2.4 \%$ of all tumors in children and adolescents (2). The majority of cases of OS affect the long bones, particularly the metaphysis, proximal tibia, proximal humerus and distal femur (3). Although significant advancements have been achieved in surgical resection combined with radiotherapy and chemotherapy, the prognosis of patients

Correspondence to: Professor Hao Jiang, Department of Surgery, China-Japan Union Hospital of Jilin University, 126 Xiantai Road, Changchun, Jilin 130033, P.R. China

E-mail: haojiang_jilin@126.com

Key words: osteosarcoma, microRNA-376a, special AT-rich sequence-binding protein 1 with OS has only been slightly improved, with the median survival time reaching only 23 months $(4,5)$. The poor treatment outcome of patients with OS is due to local recurrence and metastasis, especially pulmonary metastasis (6). Although numerous molecular targets have been identified to be implicated in OS formation and progression, their detailed mechanisms remain unknown (7). Therefore, the mechanisms underlying OS occurrence and development must be comprehensively understood to identify effective therapeutic targets for treating OS.

MicroRNAs (miRs) are highly conserved, non-coding and small RNAs that comprise 19-23 nucleotides (8). miRs are considered critical gene regulators that directly bind to the 3'-untranslated regions (3'-UTRs) by base pairing and therefore induce mRNA degradation and/or translational suppression (9). miRs regulate $\sim 60 \%$ of all human protein coding genes, indicating that miRs serve important roles in physiological and pathological behavior, including cell proliferation, cycle, apoptosis, metastasis, embryogenesis and differentiation (10). The dysregulation of miRs has been recently reported in different types of malignancies, including OS (11), prostate cancer (12), breast cancer (13) and colorectal cancer (14). Abnormally expressed miRs may serve tumor suppressive roles or oncogenic roles in tumorigenesis and tumor development, which depend on the biological functions of their target genes (15). Therefore, the expression and roles of miRs in OS must be further investigated to identify potential therapeutic targets for the therapy of patients with OS.

miR-376a-3p (miR-376a) is dysregulated in several human cancer types and the dysregulation of miR-376a serves an important role in various cell processes, including cell proliferation, migration, invasion, metastasis and apoptosis (16-19). However, to the best of our knowledge, the expression pattern, clinical significance, specific role and detailed mechanisms of miR-376a in OS remains unclear. Therefore, the present study aimed to detect the miR-376a expression in OS and its association with clinicopathological characteristics and to determine the biological roles and regulatory mechanism of miR-376a in OS cells.

\section{Materials and methods}

Tissue samples. A total of 49 primary OS tissues and corresponding adjacent normal bone tissues were obtained from patients who underwent surgical resection in the China-Japan Union Hospital of Jilin University (Changchun, China), between 
October 2013 and March 2017. The patient characteristics are presented in Table I. No chemotherapy or radiotherapy was administered prior to surgery. All tissues were snap-frozen in liquid nitrogen $\left(-196^{\circ} \mathrm{C}\right)$ at the time of surgery and were stored in liquid nitrogen until further use. The present study was approved by the Ethics Committee of the China-Japan Union Hospital of Jilin University. In addition, written informed consent was provided by all participants.

Cell culture and transfection. A total of four human OS cell lines (HOS, SAOS-2, MG-63 and U2OS), and a normal human osteoblast hFOB1.19 cell line were acquired from the Shanghai Cell Bank of the Chinese Academy of Sciences (Shanghai, China). All cell lines were cultured at $37^{\circ} \mathrm{C}$ in a humidified atmosphere containing $5 \% \mathrm{CO}_{2}$ and were maintained in Dulbecco's modified Eagle's medium (DMEM) supplemented with 10\% fetal bovine serum (FBS; both from HyClone; GE Healthcare Life Sciences, Logan, UT, USA), 100 U/ml penicillin and $100 \mathrm{U} / \mathrm{ml}$ streptomycin (Sigma-Aldrich; Merck KGaA, Darmstadt, Germany).

miR-376a mimic and miR mimic negative controls (miR-NC) were synthesized and purchased from the Shanghai GenePharma Co., Ltd. (Shanghai, China). The miR-376a mimic sequence was 5'-AUCAUAGAGGAAAAU CCACGU-3' and the miR-NC sequence was 5'-UUCUCC GAACGUGUCACGUTT-3'. SATB1 overexpression vector pcDNA3.1-SATB1 and control empty vector pcDNA3.1 were ordered from GeneCopoeia Inc., (Rockville, MD, USA). For transfection, MG-63 and U2OS cells were plated into 6-well plates with a density of $5 \times 10^{5} /$ well and grown in culture medium without antibiotics. MG-63 and U2OS cells were transfected with miR-376a mimic (100 pmol), miR-NC (100 pmol), pcDNA3.1-SATB1 $(4 \mu \mathrm{g})$ or pcDNA3.1 $\left(4 \mu \mathrm{g}\right.$ ) by using Lipofectamine ${ }^{\circledR} 2000$ (Invitrogen; Thermo Fisher Scientific, Inc., Waltham, MA, USA), following the manufacturer's protocol. After transfection $48 \mathrm{~h}$, reverse transcription-quantitative polymerase chain reaction (RT-qPCR) was performed to detect miR-376a expression. MTT and invasion assays were carried out at $24 \mathrm{~h}$ and $48 \mathrm{~h}$ posttransfection. Western blot analysis was performed to detect SATB1 protein expression at $72 \mathrm{~h}$ following transfection.

$R T$-qPCR analysis. The total RNA was isolated from the cells or tissues using the TRIzol ${ }^{\circledR}$ reagent (Invitrogen; Thermo Fisher Scientific, Inc.). miR complementary DNA (cDNA) was produced using a TaqMan MicroRNA Assay kit (Applied Biosystems; Thermo Fisher Scientific, Inc.). The temperature protocol for reverse transcription was as follows: $16^{\circ} \mathrm{C}$ for $30 \mathrm{~min}, 42^{\circ} \mathrm{C}$ for $30 \mathrm{~min}$ and $85^{\circ} \mathrm{C}$ for $5 \mathrm{~min}$. Quantification of miR-376a was performed using a TaqMan MicroRNA assay (Applied Biosystems; Thermo Fisher Scientific, Inc.). The cycling conditions were as follows: $50^{\circ} \mathrm{C}$ for $2 \mathrm{~min}, 95^{\circ} \mathrm{C}$ for $10 \mathrm{~min}$; 40 cycles of denaturation at $95^{\circ} \mathrm{C}$ for $15 \mathrm{sec}$; and annealing/extension at $60^{\circ} \mathrm{C}$ for $60 \mathrm{sec}$. To quantify the SATB1 mRNA, the total RNA was reverse transcribed into cDNA using a PrimeScripts RT reagent kit and qPCR was conducted using SYBR-Green Premix Ex Taq II (both from Takara Biotechnology Co., Ltd., Dalian, China). The temperature protocol for reverse transcription was as follows: $37^{\circ} \mathrm{C}$ for $15 \mathrm{~min}$ and $85^{\circ} \mathrm{C}$ for $5 \mathrm{sec}$. The amplification was performed
Table I. Association between miR-376a and clinicopathological features of osteosarcoma patients.

\begin{tabular}{lccc}
\hline & \multicolumn{2}{c}{ miR-376a expression } & \\
\cline { 2 - 3 } $\begin{array}{l}\text { Clinicopathological } \\
\text { features }\end{array}$ & Low (n=25) & High (n=24) & P-value \\
\hline $\begin{array}{l}\text { Age (years) } \\
<20\end{array}$ & 16 & 13 & 0.567 \\
$\geq 20$ & 9 & 11 & \\
Gender & & & 0.377 \\
$\quad$ Male & 14 & 17 & \\
Female & 11 & 7 & \\
$\begin{array}{l}\text { Tumor size (cm) } \\
<8\end{array}$ & 7 & 15 & 0.022 \\
$\geq 8$ & 18 & 9 & \\
$\begin{array}{l}\text { Location of the } \\
\text { primary tumor }\end{array}$ & & & 0.289 \\
$\quad \begin{array}{l}\text { Tibia/femur } \\
\text { Elsewhere }\end{array}$ & 22 & 18 & \\
$\begin{array}{l}\text { Lymph node } \\
\text { infiltration }\end{array}$ & 3 & 6 & \\
$\begin{array}{l}\text { No } \\
\text { Yes }\end{array}$ & & & 0.001 \\
\hline
\end{tabular}

with cycling conditions as follows: $5 \mathrm{~min}$ at $95^{\circ} \mathrm{C}$, followed by 40 cycles of $95^{\circ} \mathrm{C}$ for $30 \mathrm{sec}$ and $65^{\circ} \mathrm{C}$ for $45 \mathrm{sec}$. The primers were designed as follows: miR-376a, 5'-GTGCAGGGTCCG AGGT-3' (forward) and 5'-ATCATAGAGGAAAATCCACG-3' (reverse); U6, 5'-CTCGCTTCGGCAGCACA-3' (forward) and 5'-AACGCTTCACGAATTTGCGT-3' (reverse); SATB1, 5'-AGAGGAAGGCTTGGGAGTA-3' (forward) and 5'-GGG CAGCAGAGCTATGTG-3' (reverse); and GAPDH, 5'-CGG AGTCAACGGATTTGGTCGTAT-3' (forward) and 5'-AGC CTTCTCCATGGTGGTGAAGAC-3' (reverse). U6 snRNA and GAPDH were used as the internal control for miR-376a and SATB1 mRNA, respectively. Data were analyzed by $2^{-\Delta \Delta C q}$ method (20).

MTT assay. Following transfection for $24 \mathrm{~h}$, the cells were re-suspended and inoculated into 96 -well plates at a density of $3 \times 10^{3}$ cells per well. The cells were incubated at $37^{\circ} \mathrm{C}$ under a humidified atmosphere containing $5 \% \mathrm{CO}_{2}$ for $0-72 \mathrm{~h}$. An MTT assay was performed every $24 \mathrm{~h}$ to detect cell proliferation. A total of $10 \mu \mathrm{l}$ MTT solution (Sigma-Aldrich; Merck KGaA) was added to each well and the cells were incubated for $4 \mathrm{~h}$ at $37^{\circ} \mathrm{C}$. After the supernatant was discarded, $100 \mu$ l dimethyl sulfoxide (Sigma-Aldrich; Merck KGaA), which was used to resolve the crystalline formazan, was added to each well. The absorbance at a wavelength of $490 \mathrm{~nm}$ was monitored with a microplate reader (Bio-Rad Laboratories, Inc., Hercules, CA, USA).

Invasion assay. The transfected cells were digested at $48 \mathrm{~h}$ post-transfection, washed with PBS and suspended in FBS-free DMEM medium. A total of $1 \times 10^{5}$ cells in FBS-free DMEM were seeded into the upper chamber of Transwell 

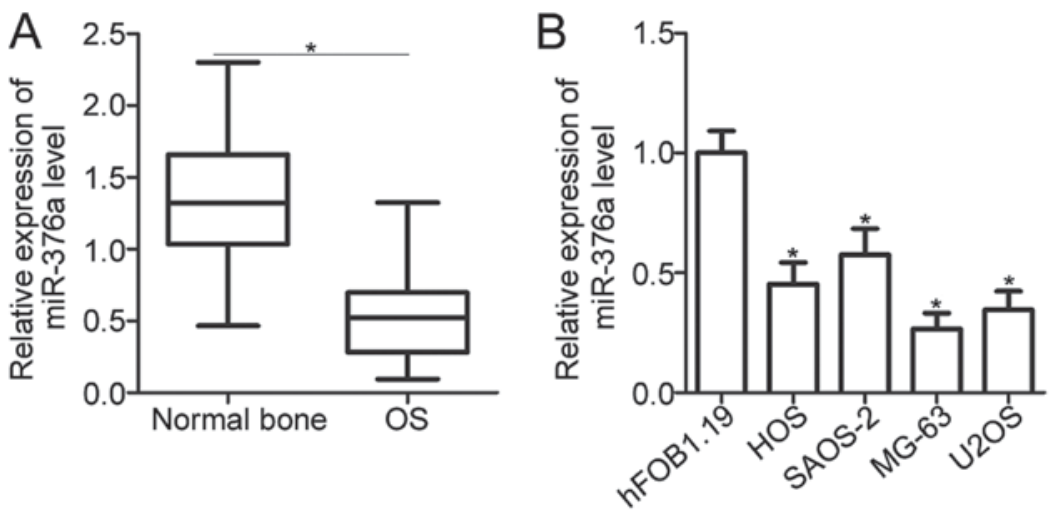

Figure 1. miR-376a expression is downregulated in OS. (A) Reverse transcription-quantitative polymerase chain analysis was utilized to detect miR-376a expression in 49 pairs of OS tissues and adjacent normal bone tissues. "P $<0.05$ vs. the normal bone tissues. (B) The expression level of miR-376a was determined in four human OS cell lines, namely, HOS, SAOS-2, MG-63 and U2OS, as well as the normal human osteoblast hFOB1.19 cell line. "P<0.05 vs. hFOB1.19. miR, microRNA; OS, osteosarcoma.

plates (Corning Inc., Corning, NY, USA), which were pre-coated with Matrigel (BD Biosciences, Franklin Lakes, NJ, USA). Subsequently, $500 \mu 1$ DMEM supplemented with $10 \%$ FBS was added to the lower chamber of the Transwell plates. Following $24 \mathrm{~h}$ of culture at $37^{\circ} \mathrm{C}$, the cells remaining on the top of the chamber were removed using cotton swabs. The invasive cells were fixed with $4 \%$ paraformaldehyde at room temperature for $20 \mathrm{~min}$ and stained with $0.05 \%$ crystal violet at room temperature for $20 \mathrm{~min}$. A total of five fields per chamber were randomly selected and the number of invasive cells was counted under an inverted light microscope (x200; Olympus Corporation, Tokyo, Japan).

Target genes of miR-376a. TargetScan Human 7.0 (http://www. targetscan.org/) and miRBase (http://www.mirbase.org/) were employed to predict the putative targets of miR-376a.

Luciferase reporter assay. A wild-type (Wt) fragment of the 3'-UTR of SATB1 containing the predicted miR-376a binding sequences and its mutated (Mut) sequence was chemically produced by Shanghai GenePharma Co., Ltd., and cloned into pMIR-GLO ${ }^{\mathrm{TM}}$ Luciferase vector (Promega Corporation, Madison, WI, USA). The Wt and Mut luciferase plasmids were defined as pMIR-SATB1-3'-UTR Wt and pMIR-SATB1-3'-UTR Mut, respectively. Cells were seeded into 24-well plates with a density of $1.5 \times 10^{5} /$ well and cotransfected with miR-376a mimic or miR-NC, and pMIR-SATB1-3'-UTR Wt or pMIR-SATB1-3'-UTR Mut, using Lipofectamine 2000 according to the manufacturer's protocol. Following transfection for 2 days, the dual-Luciferase Reporter Assay System (Promega Corporation) was applied to measure the luciferase activities, according to the manufacturer's protocol. Firefly luciferase activity was normalized to Renilla luciferase activity.

Western blot analysis. Tissue samples or cells were solubilized in cold radioimmunoprecipitation assay lysis buffer (Beyotime Institute of Biotechnology, Shanghai, China). The total protein concentration was determined using a Bicinchoninic Acid Protein Assay kit (Pierce Biotechnology, Inc., Rockford, IL, USA). Equal amounts of proteins $(20 \mu \mathrm{g})$ were separated using $10 \%$ SDS-PAGE, electrotransferred to polyvinylidene fluoride membranes (EMD Millipore, Billerica, MA, USA) and blocked at room temperature for $2 \mathrm{~h}$ in Tris-buffered saline with $0.5 \%$ Tween (TBST) buffer containing 5\% dried skimmed milk. Following being washed three times with TBST, the membranes were incubated with rabbit anti-human monoclonal SATB1 antibody (cat. no. ab109122; 1:1,000; Abcam, Cambridge, MA, USA) or rabbit anti-human monoclonal GAPDH antibody (cat. no. ab181603; 1:1,000; Abcam) at $4^{\circ} \mathrm{C}$ overnight. Afterwards, the membranes were washed three times with TBST and further incubated with goat anti-rabbit horseradish peroxidase-conjugated secondary antibody (cat. no. ab6721; 1:5,000; Abcam) at room temperature for $1 \mathrm{~h}$. Finally, an ECL Protein Detection kit (Pierce Biotechnology, Inc., Rockford, IL, USA) was used to visualize the protein bands. GADPH was used as the loading control. Protein expression was quantified using Quantity One software version 4.62 (Bio-Rad Laboratories, Inc.).

Statistical analysis. Data were presented as the mean \pm standard deviation of at least 3 independent experiments and analyzed with SPSS software, version 21.0 (IBM SPSS, Armonk, NY, USA). The association between miR-376a expression and clinicopathological characteristics of OS was evaluated by a $\chi^{2}$ test. The two-tailed Student's t-test and one-way analysis of variance combined with Student-Newman-Keuls were used to compare differences between groups. Spearman's correlation analysis was carried out to reveal the correlation between expression levels of miR-376a and SATB1 mRNA in OS tissues. $\mathrm{P}<0.05$ was considered to indicate a statistically significant difference.

\section{Results}

miR-376a expression is decreased in OS tissues and cell lines. To understand the expression pattern of miR-376a in OS, miR-376a expression was initially measured in 49 pairs of OS tissues and adjacent normal bone tissues. RT-qPCR analysis revealed that miR-376a was significantly downregulated in OS tissues compared with the adjacent normal bone tissues $(\mathrm{P}<0.05$; Fig. 1A). Subsequently, the clinical significance of miR-376a expression in OS was investigated. 

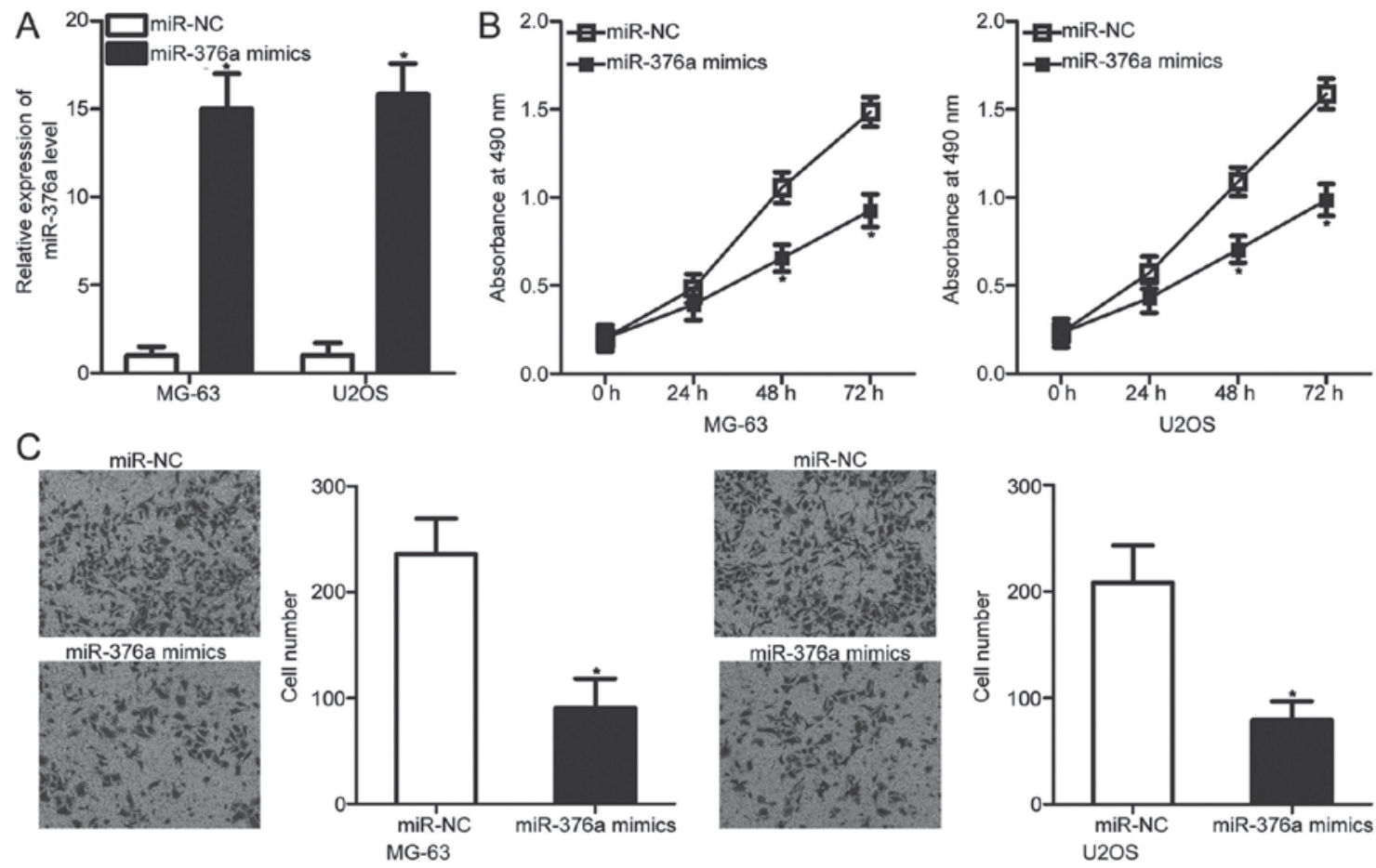

Figure 2. miR-376a overexpression inhibits proliferation and invasion of MG-63 and U2OS cells. (A) MG-63 and U2OS cells were transfected with miR-376a mimic or miR-NC. The transfection efficiency was quantified using reverse transcription-quantitative polymerase chain reaction. ${ }^{*} \mathrm{P}<0.05 \mathrm{vs}$. miR-NC. (B) MTT assay was used to detect the proliferation of MG-63 and U2OS cells transfected with miR-376a mimic or miR-NC. "P<0.05 vs. miR-NC. (C) The effect of miR-376a overexpression on the invasion abilities of MG-63 and U2OS cells was evaluated using an invasion assay. " $\mathrm{P}<0.05$ vs. miR-NC. miR, microRNA; miR-NC, microRNA negative control.

A

SATB1-3'-UTR Wt

5'... UUUAUGAGUUUAUGGCUAUGGAA... 3'

3' UGCACCUAAAAGGAGAUACUA 5'

hsa-miR-376a

5'...UUUAUGAGUUUAUGgGAUACUAA.... SATB1-3'-UTR Mut

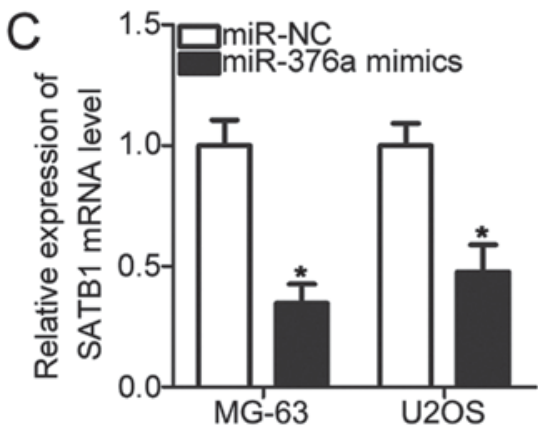

$\mathrm{B}$
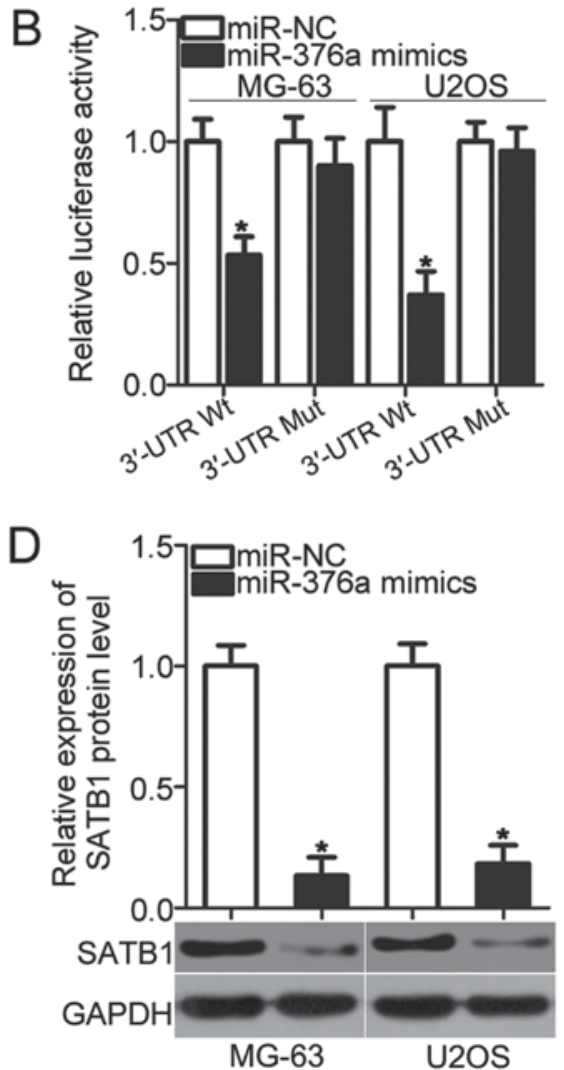

Figure 3. SATB1 is a direct target gene of miR-376a in OS cells. (A) miR-376a putative Wt binding sequences and corresponding Mut sequences in the 3'-UTR of SATB1. (B) Luciferase activity was quantified in MG-63 and U2OS cells co-transfected with miR-376a mimic or miR-NC, and pMIR-SATB1-3'-UTR Wt or pMIR-SATB1-3'-UTR Mut. "P<0.05 vs. miR-NC. The expression levels of SATB1 were detected in MG-63 and U2OS cells transfected with miR-376a mimic or miR-NC by (C) reverse transcription-quantitative polymerase chain reaction and (D) western blot analysis. "P<0.05 vs. miR-NC. miR, microRNA; miR-NC, microRNA negative control; Mut, mutant; Wt, wild-type; OS, osteosarcoma cells; UTR, untranslated region; SATB1, special AT-rich sequence-binding protein 1. 
A
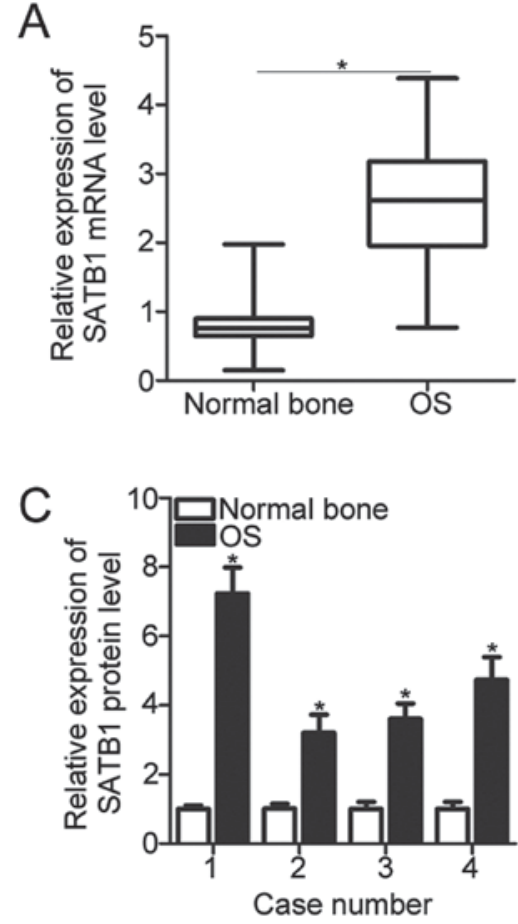
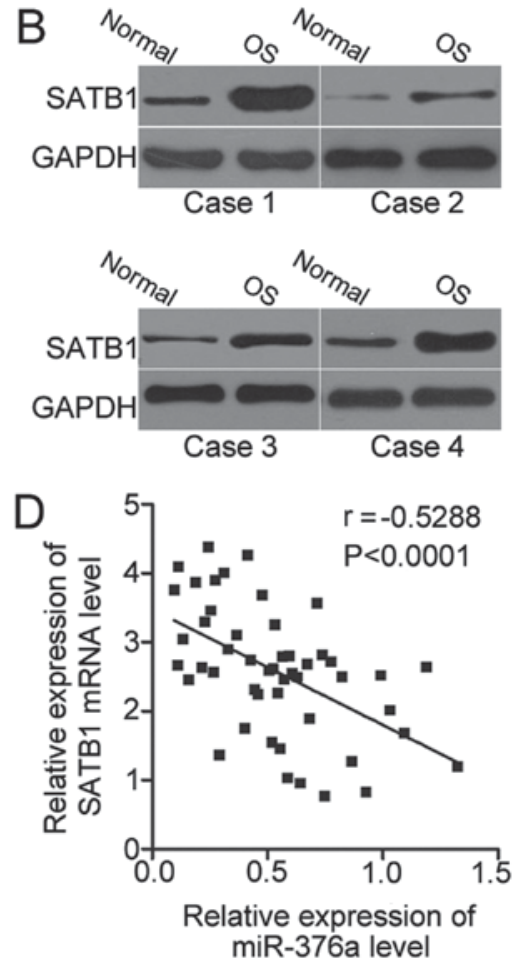

Figure 4. miR-376a expression is negatively correlated with SATB1 mRNA level in OS tissues. (A) The mRNA and (B) protein levels of SATB1 in OS tissues and adjacent normal bone tissues were quantified using reverse transcription-quantitative polymerase chain reaction and western blot analysis, respectively (C) Densitometry data from the western blotting. ${ }^{*} \mathrm{P}<0.05$ vs. the normal bone tissues. (D) Spearman's correlation analysis was performed to investigate the association between miR-376a and SATB1 mRNA expression in OS tissues. $\mathrm{r}=-0.5288, \mathrm{P}<0.0001$. OS, osteosarcoma; miR, microRNA; SATB1, special AT-rich sequence-binding protein 1.

The median value of miR-376a expression was defined as the cutoff point and this cutoff point was used to divide all OS patients into a low miR-376a expression group $(n=25)$ or a high miR-376a expression group $(n=24)$. A low miR-376a level was significantly correlated with tumor size $(\mathrm{P}=0.022)$ and lymph node infiltration $(\mathrm{P}=0.001)$ in OS but was not associated with age, gender, and location of the primary tumor (all $\mathrm{P}>0.05$; Table I). In addition, the expression of miR-376a in four human OS cell lines, namely, HOS, SAOS-2, MG-63 and U2OS, as well as a normal human osteoblast hFOB1.19 cell line, was determined. As indicated in Fig. 1B, the expression level of miR-376a in all OS cell lines was significantly decreased compared with in hFOB1.19 $(\mathrm{P}<0.05)$. These results suggested that reduced expression of miR-376a may be associated with OS progression.

miR-376a upregulation prohibits the proliferation and invasion of OS cells. To determine whether miR-376a can affect the malignant phenotypes of OS cells, MG-63 and U2OS cells, which exhibited relatively lower miR-376a expression among the four OS cell lines, were transfected with an miR-376a mimic or miR-NC. Transfection with the miR-376a mimic significantly increased the miR-376a levels in MG-63 and U2OS cells when compared with the cells transfected with miR-NC $(\mathrm{P}<0.05$; Fig. 2A). MTT and invasion assays were used to examine the effects of miR-376a overexpression on OS cell proliferation and invasion, respectively. The results revealed that ectopic expression of miR-376a significantly inhibited the proliferation $(\mathrm{P}<0.05$; Fig. $2 \mathrm{~B})$ and invasion $(\mathrm{P}<0.05$; Fig. 2C) of MG-63 and U2OS cells compared with the miR-NC groups. These results suggested that miR-376a may serve a tumor suppressive role in OS progression.

miR-376a directly targets SATB1 and inhibits its expression in OS cells. To illustrate the molecular mechanism by which miR-376a inhibits OS cell proliferation and invasion, bioinformatics analysis was conducted to predict the potential targets of miR-376a. SATB1 was predicted as a primary target of miR-376a (Fig. 3A) and was chosen for additional confirmation analysis due to its regulatory roles in OS pathogenesis and development $(21,22)$. To confirm this prediction, luciferase reporter assays were conducted in MG-63 and U2OS cells, which were transfected with pMIR-SATB1-3'-UTR Wt or pMIR-SATB1-3'-UTR Mut, together with the miR-376a mimic or miR-NC. Upregulation of $\mathrm{miR}-376$ a reduced the luciferase activities of the plasmid carrying the Wt 3'-UTR of SATB1 in MG-63 and U2OS cells $(\mathrm{P}<0.05)$ but had no effect on that of the Mut 3'-UTR of SATB1 (Fig. 3B). Furthermore, the effects of miR-376a overexpression on endogenous SATB1 expression were determined using RT-qPCR and western blot analysis, respectively. As expected, SATB1 mRNA ( $\mathrm{P}<0.05$; Fig. $3 \mathrm{C}$ ) and protein $(\mathrm{P}<0.05$; Fig. 3D) levels were significantly reduced in MG-63 and U2OS cells transfected with miR-376a mimic. Therefore, SATB1 is a direct target gene of miR-376a in OS.

SATB1 expression is upregulated in OS and inversely correlated with miR-376a expression. SATB1 was validated as a direct target gene of miR-376a in OS. Therefore, the SATB1 expression was detected in 49 pairs of OS tissues and adjacent normal bone tissues using RT-qPCR. The expression level of 
A
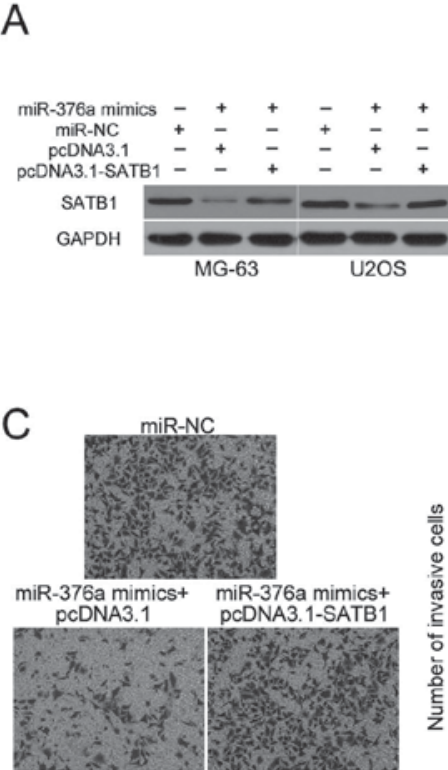

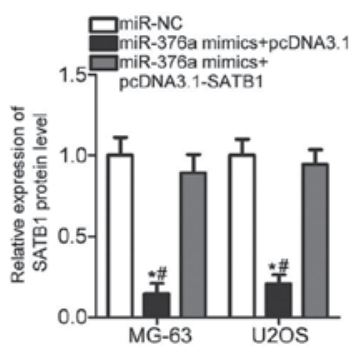

B
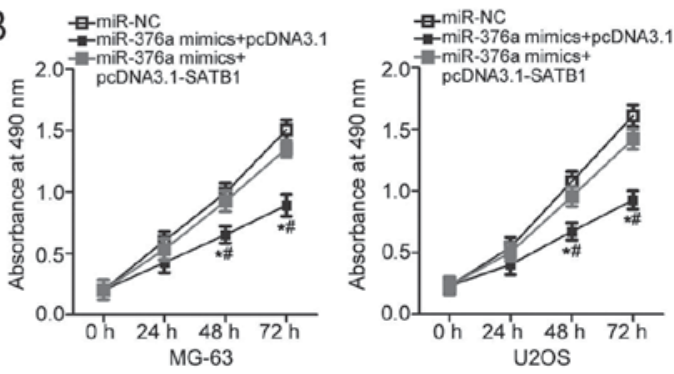
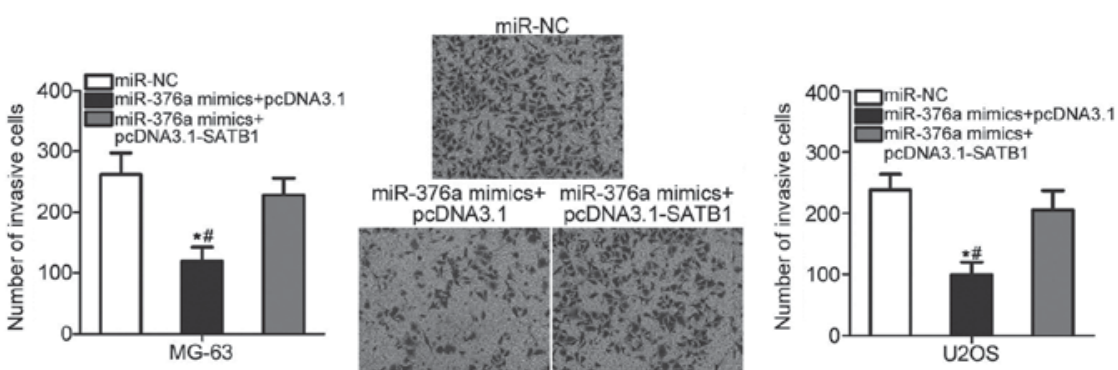

Figure 5. Recovered SATB1 expression rescues OS cells from the inhibitory effects of miR-376a overexpression. (A) MG-63 and U2OS cells were transfected with miR-NC, miR-376a mimic+pcDNA3.1 or miR-376a mimic+pcDNA3.1-SATB1. Following transfection for $72 \mathrm{~h}$, SATB1 protein expression was detected using western blot analysis. ${ }^{*} \mathrm{P}<0.05$ vs. miR-NC. ${ }^{~} \mathrm{P}<0.05$ vs. miR-376a mimic+pcDNA3.1-SATB1. The (B) proliferation and (C) invasion of indicated cells was examined using MTT and invasion assays, respectively. "P<0.05 vs. miR-NC. "P<0.05 vs. miR-376a mimic+pcDNA3.1-SATB1. miR, microRNA; miR-NC, microRNA negative control; SATB1, special AT-rich sequence-binding protein 1; OS, osteosarcoma.

SATB1 was significantly upregulated in OS tissues compared with the adjacent normal bone tissues $(\mathrm{P}<0.05$; Fig. $4 \mathrm{~A})$. In addition, the SATB1 protein expression was also determined in several pairs of OS tissues and adjacent normal bone tissues chosen at random using western blot analysis. As demonstrated in Fig. 4B, the SATB1 protein expression in OS tissues was significantly increased compared with the adjacent normal bone tissues in the 4 cases tested $(\mathrm{P}<0.05$; Fig. $4 \mathrm{~B}$ and $\mathrm{C})$. Furthermore, miR-376a expression was inversely correlated with SATB1 mRNA levels in OS tissues $(\mathrm{P}<0.0001 ; \mathrm{r}=-0.5288$; Fig. 4D). These results further suggested that SATB1 is a direct target gene of miR-376a in OS.

SATB1 overexpression attenuates the suppressive effects of miR-376a on OS cell proliferation and invasion. Rescue experiments were performed to assess whether SATB1 mediated the inhibitory roles of miR-376a in OS. miR-376a-overexpressing MG-63 and U2OS cells were co-transfected with a SATB1 overexpression vector pcDNA3.1-SATB1 or control empty vector pcDNA3.1. The decreased expression level of SATB1 induced by miR-376a overexpression was recovered in MG-63 and U2OS cells co-transfected with pcDNDA3.1-SATB1 $(\mathrm{P}<0.05$; Fig. 5A). MTT and invasion assays revealed that restored SATB1 expression eliminated the inhibitory effects of miR-376a overexpression on the proliferation $(\mathrm{P}<0.05$; Fig. 5B) and invasion ( $\mathrm{P}<0.05$; Fig. 5C) of MG-63 and U2OS cells. These results suggested that miR-376a serves a tumor suppressive role in OS partly by inhibiting SATB1 expression.

\section{Discussion}

Aberrantly expressed miRs are implicated in the regulation of OS onset and development (23-25). Therefore, key miRs in OS must be identified to develop promising and effective therapeutic targets for patients with OS. In the present study, the expression level and clinical significance of miR-376a in OS was measured and the roles, and associated regulatory mechanism of miR-376a were determined in OS. The results demonstrated that miR-376a expression was downregulated in OS tissues and cell lines. Decreased expression of miR-376a was associated with tumor size and lymph node infiltration of OS patients. In addition, miR-376a overexpression restricted cell proliferation and invasion in OS. Furthermore, SATB1 was confirmed as a direct target gene of miR-376a in OS. Additionally, SATB1 expression was significantly overexpressed in OS tissues and this overexpression was inversely correlated with miR-376a levels in OS tissues. Reintroduction of SATB1 expression rescued OS cells from the tumor suppressive roles of miR-376a. These results revealed that miR-376a may serve as a tumor suppressor in OS by directly targeting SATB1.

Significant alterations in miR-376a expression have been observed in multiple human cancer types. For instance, miR-376a is under-expressed in glioma tissues, cell lines and serum $(16,26)$. Low miR-376a expression is correlated with the World Health Organization grade and KPS score of glioma patients. In addition, miR-376a is validated as an independent factor that predicts the poor prognosis of glioma patients (26). In hepatocellular carcinoma, miR-376a is downregulated in tumor tissues and this downregulation is associated with $\alpha$-fetoprotein levels (17). In colorectal cancer, the expression level of miR-376a in tumor tissues is decreased compared with the adjacent normal mucosa. Low miR-376a expression is associated with lymph node metastasis of colorectal cancer patients. Colorectal cancer patients with low miR-376a expression present lower survival rates compared with patients with high miR-376a levels (27). Low expression of miR-376a has also been observed in prostate cancer (18) and non-small-cell 
lung cancer (19). Conversely, miR-376a is overexpressed in ovarian cancer. High miR-376a expression is significantly associated with the clinical stage and the International Federation of Gynaecological Oncologists stage of ovarian cancer $(28,29)$. These conflicting results indicate that the expression patterns of miR-376a exhibit tissue specificity and suggest that miR-376a may be developed as a meaningful prognostic biomarker for predicting the prognosis of patients with these human cancer types.

Differently expressed miRs have been associated with the carcinogenesis and cancer progression of several human malignancies. For instance, miR-376a suppresses the proliferation and invasion of glioblastoma multiform cells (16). Zheng et al (17) reported that miR-376a overexpression inhibits cell proliferation and promotes apoptosis in hepatocellular carcinoma. Formosa et al (18) demonstrated that the resumption of miR-376a expression attenuates the growth of prostate cancer cells while inducing apoptosis. Wang et al (19) indicated that miR-376a re-expression restricts cell proliferation and invasion while promoting apoptosis in non-small-cell lung cancer. Conversely, miR-376a serves oncogenic roles in ovarian cancer by promoting cell proliferation and motility, inhibiting cell apoptosis in vitro and increasing tumor growth in vivo (29). These studies suggested that miR-376a may be a potential therapeutic target for patients with these human malignancies.

Previous studies have identified several direct targets of miR-376a, including SP1 (16) in glioblastoma multiform, $\mathrm{p} 85 \alpha$ (17) and H3K18 (30) in hepatocellular carcinoma, frizzled-4 in prostate cancer (18), c-Myc (19) in non-small-cell lung cancer, Krueppel-like factor 15 (29) and Caspase-8 (29) in ovarian cancer. SATB1, which is a cell type-specific nuclear matrix attachment region binding protein, was a direct target gene of miR-376a in OS. SATB1 is reportedly upregulated in several types of cancer, including hepatocellular carcinoma (31), ovarian cancer (32), gastric cancer (33), prostate cancer (34) and colorectal cancer (35). The expression of SATB1 was also upregulated in OS tissues and cell lines. The overexpression of SATB1 contributes to OS progression by promoting cell proliferation, migration and invasion, inhibiting apoptosis and reducing the chemosensitivity of cells to arsenic trioxide $(21,22)$. These results suggest that knockdown of SATB1 may be a valuable therapeutic strategy for the treatment of patients with OS.

In conclusion, miR-376a expression was downregulated in OS tissues and cell lines, and the low miR-376a expression in OS was significantly associated with the tumor size and lymph node infiltration. In addition, forced expression of miR-376a repressed OS cell proliferation and invasion by directly targeting SATB1. Therefore, the results of the present study suggest that miR-376a may be a promising therapeutic target for treating patients with OS.

\section{Acknowledgements}

Not applicable.

\section{Funding}

No funding was received.

\section{Availability of data and materials}

The datasets used and/or analyzed during the present study are available from the corresponding author on reasonable request.

\section{Authors' contributions}

HJ designed the present study. GZ and LM performed the functional experiments. LM analyzed the data of this study. All authors have read and approved the final draft.

\section{Ethics approval and consent to participate}

The present study was approved by the Research Ethics Committee of China-Japan Union Hospital of Jilin University (Jilin, China) and was performed in accordance with the Declaration of Helsinki and the guidelines of the Ethics Committee of China-Japan Union Hospital of Jilin University. Written informed consent was obtained from all patients for the use of their clinical tissues.

\section{Patient consent for publication}

Written informed consent was obtained from all patients for the use of their clinical tissues.

\section{Competing interests}

The authors declare that they have no competing interests.

\section{References}

1. Maximov VV and Aqeilan RI: Genetic factors conferring metastasis in osteosarcoma. Future Oncol 12: 1623-1644, 2016.

2. Mirabello L, Troisi RJ and Savage SA: Osteosarcoma incidence and survival rates from 1973 to 2004: Data from the surveillance, epidemiology, and end results program. Cancer 115: 1531-1543, 2009.

3. Ritter J and Bielack SS: Osteosarcoma. Ann Oncol 21 (Suppl 7): vii320-vii325, 2010.

4. Liebner DA: The indications and efficacy of conventional chemotherapy in primary and recurrent sarcoma. J Surg Oncol 111: 622-631, 2015.

5. Fagioli F, Aglietta M, Tienghi A, Ferrari S, Brach del Prever A, Vassallo E, Palmero A, Biasin E, Bacci G, Picci P and Madon E: High-dose chemotherapy in the treatment of relapsed osteosarcoma: An Italian sarcoma group study. J Clin Oncol 20: 2150-2156, 2002.

6. Bacci G, Balladelli A, Palmerini E, Alberghini M, Pollastri P, Galletti S, Mercuri M and Picci P: Neoadjuvant chemotherapy for osteosarcoma of the extremities in preadolescent patients: The Rizzoli Institute experience. J Pediatr Hematol Oncol 30: 908-912, 2008.

7. Dong J, Liu Y, Liao W, Liu R, Shi P and Wang L: miRNA-223 is a potential diagnostic and prognostic marker for osteosarcoma. J Bone Oncol 5: 74-79, 2016.

8. Berindan-Neagoe I and Calin GA: Molecular pathways: microRNAs, cancer cells, and microenvironment. Clin Cancer Res 20: 6247-6253, 2014.

9. Ambros V: The functions of animal microRNAs. Nature 431: 350-355, 2004.

10. Sassen S, Miska EA and Caldas C: MicroRNA: Implications for cancer. Virchows Arch 452: 1-10, 2008.

11. Cai W, Jiang H, Yu Y, Xu Y, Zuo W, Wang S and Su Z: miR-367 regulation of DOC-2/DAB2 interactive protein promotes proliferation, migration and invasion of osteosarcoma cells. Biomed Pharmacother 95: 120-128, 2017

12. Fu F, Wan X, Wang D, Kong Z, Zhang Y, Huang W, Wang C, $\mathrm{Wu} \mathrm{H}$ and Li Y: MicroRNA-19a acts as a prognostic marker and promotes prostate cancer progression via inhibiting VPS37A expression. Oncotarget 9: 1931-1943, 2018. 
13. Yang Y, Jiang Z, Ma N, Wang B, Liu J, Zhang L and Gu L: MicroRNA-223 Targeting STIM1 inhibits the biological behavior of breast cancer. Cell Physiol Biochem 45: 856-866, 2018.

14. Du B, Wu D, Yang X, Wang T, Shi X, Lv Y, Zhou Z, Liu Q and Zhang W: The expression and significance of microRNA in different stages of colorectal cancer. Medicine (Baltimore) 97: e9635, 2018.

15. Macfarlane LA and Murphy PR: MicroRNA: Biogenesis, function and role in cancer. Curr Genomics 11: 537-561, 2010.

16. Li Y, Wu Y, Sun Z, Wang R and Ma D: MicroRNA376a inhibits cell proliferation and invasion in glioblastoma multiforme by directly targeting specificity protein 1 . Mol Med Rep 17: $1583-1590,2018$.

17. Zheng Y, Yin L, Chen H, Yang S, Pan C, Lu S, Miao M and Jiao B: miR-376a suppresses proliferation and induces apoptosis in hepatocellular carcinoma. FEBS Lett 586: 2396-2403, 2012.

18. Formosa A, Markert EK, Lena AM, Italiano D, Finazzi-Agro' E, Levine AJ, Bernardini S, Garabadgiu AV, Melino G and Candi E: MicroRNAs, miR-154, miR-299-5p, miR-376a, miR-376c, miR-377, miR-381, miR-487b, miR-485-3p, miR-495 and miR-654-3p, mapped to the $14 \mathrm{q} 32.31$ locus, regulate proliferation, apoptosis, migration and invasion in metastatic prostate cancer cells. Oncogene 33: 5173-5182, 2014.

19. Wang Y, Cong W, Wu G, Ju X, Li Z, Duan X, Wang X and Gao H: MiR-376a suppresses the proliferation and invasion of non-small-cel lung cancer by targeting c-Myc. Cell Biol Int 42: 25-33, 2018.

20. Livak KJ and Schmittgen TD: Analysis of relative gene expression data using real-time quantitative PCR and the 2(-Delta Delta C(T)) method. Methods 25: 402-408, 2001.

21. Zhang H, Qu S, Li S, Wang Y, Li Y, Wang Y, Wang Z and Li R Silencing SATB1 inhibits proliferation of human osteosarcoma U2OS cells. Mol Cell Biochem 378: 39-45, 2013.

22. Zhang H, Su X, Guo L, Zhong L, Li W, Yue Z, Wang X, Mu Y, Li X, Li R and Wang Z: Silencing SATB1 inhibits the malignant phenotype and increases sensitivity of human osteosarcoma U2OS cells to arsenic trioxide. Int J Med Sci 11: 1262-1269, 2014

23. Li X, Sun X, Wu J and Li Z: MicroRNA-613 suppresses proliferation, migration and invasion of osteosarcoma by targeting c-MET. Am J Cancer Res 6: 2869-2879, 2016.

24. Qu Q, Chu X and Wang P: MicroRNA-195-5p suppresses osteosarcoma cell proliferation and invasion by suppressing naked cuticle homolog 1. Cell Biol Int 41: 287-295, 2017.
25. Ren X, Shen Y, Zheng S, Liu J and Jiang X: miR-21 predicts poor prognosis in patients with osteosarcoma. Br J Biomed Sci 73: $158-162,2016$.

26. Huang Q, Wang C, Hou Z, Wang G, Lv J, Wang H, Yang J, Zhang $Z$ and Zhang H: Serum microRNA-376 family as diagnostic and prognostic markers in human gliomas. Cancer Biomark 19: 137-144, 2017.

27. Mo ZH, Wu XD, Li S, Fei BY and Zhang B: Expression and clinical significance of microRNA-376a in colorectal cancer. Asian Pac J Cancer Prev 15: 9523-9527, 2014.

28. Meng X, Joosse SA, Muller V, Trillsch F, Milde-Langosch K, Mahner S, Geffken M, Pantel K and Schwarzenbach H: Diagnostic and prognostic potential of serum miR-7, miR-16, miR-25, miR-93, miR-182, miR-376a and miR-429 in ovarian cancer patients. Br J Cancer 113: 1358-1366, 2015.

29. Yang L, Wei QM, Zhang XW, Sheng Q and Yan XT: MiR-376a promotion of proliferation and metastases in ovarian cancer: Potential role as a biomarker. Life Sci 173: 62-67, 2017.

30. Zheng Y, Chen H, Yin M, Ye X, Chen G, Zhou X, Yin L, Zhang C and Ding B: MiR-376a and histone deacetylation 9 form a regulatory circuitry in hepatocellular carcinoma. Cell Physiol Biochem 35: 729-739, 2015.

31. Tu W, Luo M, Wang Z, Yan W, Xia Y, Deng H, He J, Han P and Tian D: Upregulation of SATB1 promotes tumor growth and metastasis in liver cancer. Liver Int 32: 1064-1078, 2012.

32. Xiang J, Zhou L, Li S, Xi X, Zhang J, Wang Y, Yang Y, Liu X and Wan X: AT-rich sequence binding protein 1: Contribution to tumor progression and metastasis of human ovarian carcinoma. Oncol Lett 3: 865-870, 2012.

33. Lu X, Cheng C, Zhu S, Yang Y, Zheng L, Wang G, Shu X, Wu K, Liu K and Tong Q: SATB1 is an independent prognostic marker for gastric cancer in a Chinese population. Oncol Rep 24: 981-987, 2010.

34. Mao L, Yang C, Wang J, Li W, Wen R, Chen J and Zheng J: SATB1 is overexpressed in metastatic prostate cancer and promotes prostate cancer cell growth and invasion. J Transl Med 11: 111, 2013.

35. Baba H, Ishikawa T, Mogushi K, Ishiguro M, Uetake H, Tanaka $H$ and Sugihara K: Identification of SATB1 as a specific biomarker for lymph node metastasis in colorectal cancer. Anticancer Res 36: 4069-4076, 2016. 